\title{
As mediações das performances: aproximações entre Adidas e Run DMC a partir do estudo de videoclipes
}

\section{Performance's mediations: relatioships between Adidas and Run DMC through videoclips analysis}

\author{
Marcio Ricardo Silva Barbosa ${ }^{1}$ \\ Jorge L. C. Cardoso Filho ${ }^{2}$
}

Resumo A reputação da marca de produtos esportivos Adidas permitiu sua incorporação ao universo simbólico de diversas subculturas urbanas ao redor do mundo. A cultura hip-hop e seus adeptos, também, se inseriram nesse contexto e vincularam, de forma bastante peculiar, a Adidas ao seu repertório de símbolos identitários. Com isto, o principal objetivo deste artigo é analisar as performances do grupo de rap norte-americano Run DMC e da Adidas, bem como as suas estratégias comunicacionais na construção e apropriação de valores culturais através da interpretação simbólica das gestualidades e figurino dos artistas que utilizam a marca em seus videoclipes. Deste modo, pretende-se discutir as contribuições do grupo e de seus videoclipes na transformação da marca alemã em um dos símbolos de ostentação e consumo de uma cultura originária de comunidades negras americanas.

Palavras-chave: Performance; Videoclipe; Mapa das mediações

\begin{abstract}
The reputation of Sporting goods brand Adidas allowed its incorporation into the symbolic universe of different urban subcultures around the world. The hip-hop culture and its adherents also inserted in this context and linked Adidas, in a peculiar way, to their repertoire of identity symbols. The main

\footnotetext{
${ }^{1}$ Universidade Federal da Bahia - UFBA, Salvador, BA, Brasil. E-mail: barbosa.marciors@gmail. com

${ }^{2}$ Universidade Federal do Recôncavo da Bahia - UFRB, Cachoeira, BA, Brasil. E-mail: cardosofilho.jorge@gmail.com
} 
objective of this paper is to analyze the performance of the North American rap group Run DMC and Adidas, as well as their communication strategies in the construction and appropriation of cultural values through the symbolic interpretation of gestures and behavior of the artists using the brand on their video clips. Thus, it intends to discuss the contributions of the group and their video clips to turn a German brand in one of the symbols of pageantry and consumption of a culture originated from american black communities.

Keywords: Performance; Video clip; Map of mediations 


\section{Adidas: um elemento da cultura hip-hop}

A marca de produtos esportivos Adidas, ao longo de sua história, construiu uma reputação que permitiu sua incorporação ao universo simbólico de diversas subculturas urbanas ao redor do mundo. A cultura hip-hop e seus adeptos também se inseriram nesse contexto e vincularam, de forma bastante peculiar, a Adidas ao seu repertório simbólico. É possível observar este fenômeno em diversos suportes midiáticos e espaços de interação e de práticas sociais de jovens artistas, fãs ou militantes do hip-hop. Em shows de rap, competições de b-boys ou até mesmo nos personagens grafitados nos muros das diversas metrópoles, assim como em videoclipes, filmes e campanhas publicitárias que retratam as práticas culturais do universo hip-hop, as três listras são encontradas como um dos elementos que estabelece a marca de identidade e de reconhecimento de tudo aquilo que se expressa através daquela cultura.

A trajetória e sucesso da marca perante o público jovem e mais especificamente entre os adeptos da cultura hip-hop, no entanto, teve como um dos grandes responsáveis o grupo de rap estadunidense Run DMC. Os rappers Run, DMC e o DJ Jam Master Jay alcançaram o sucesso em 1984 e foram responsáveis por levar o rap ao mainstream ${ }^{3}$ com o lançamento do single Rock Box. Com esta música, o Run DMC vendeu mais de um milhão de cópias do seu primeiro álbum e se tornou o primeiro grupo de rap a ter um videoclipe na grade de programação da MTV (Music Television) - que, na época, se recusava a exibir videoclipes de artistas negros, com exceção de Michael Jackson (LEAL, 2007, p. 74).

Desse modo, o Run DMC se tornou um símbolo da cultura hip-hop. Além de ser o primeiro grupo de rap a aparecer na capa de diversos jornais e da revista Rolling Stone, esteve diversas vezes entre os primeiros das paradas musicais e permaneceu com outros videoclipes na programação diária da MTV, apesar da resistência inicial da emissora. Conforme afirmam Orville Hall e Antonio Allen, no documentário

\footnotetext{
3 Entende-se por mainstream o circuito cultural dominante no campo dos meios de comunicação. Um circuito que lida com convenções associadas ao consumo em ampla escala, de maneira global, que amplia a distância de separação entre condições de produção e reconhecimento dos produtos.
} 
Walk this way (LEAL, 2007), ao estabelecer modos singulares de postura ao cantar, se vestir e se gesticular, o grupo introduziu, ainda, aos shows de rap uma performance diferente daquelas desempenhadas por outros rappers até então.

Antes do Run DMC, o figurino utilizado pelos rappers em suas apresentações era extravagante e inusitado. Contudo, eles traduziram e ressignificaram os anseios das ruas ao adotarem um novo estilo de comportamento que performatizava "um jeito durão estampado no rosto" e uma forma peculiar de cruzar os braços como demonstração de atitude. Através da utilização de correntões de ouro no pescoço, chapéu e tênis da marca Adidas, sem cadarço, contribuíram para o lançamento de tendências que, mais tarde, se tornaram itens obrigatórios nas indumentárias e nas performances dos MCs (LEAL, 2007).

Identifica-se, então, que esses rappers inauguraram uma forma de relacionamento com as marcas comerciais ainda não explorada por outros artistas do gênero e a introduziram ao universo hip-hop de modo tão significativo que a transformaram em um dos símbolos mais representativos da cultura hip-hop (STOUTE, 2011).

Esse aspecto nos faz questionar a relação entre a Adidas e o Run DMC. Como uma marca que se negou inicialmente a patrocinar o grupo - alegando não querer se vincular a uma cultura considerada marginal torna-se símbolo das práticas de consumo desse mesmo grupamento? A despeito da idolatria de seus membros e utilização espontânea dos tênis da marca, como aponta Klein (2002), como a Adidas passa a se relacionar com o gênero musical rap? Utilizamos um dos inúmeros videoclipes do grupo, onde os seus membros colocam a Adidas em posição de destaque, para analisar as suas contribuições na transformação de uma marca alemã em um dos símbolos de ostentação e consumo de uma cultura originária de comunidades negras estadunidenses.

O desafio deste artigo é analisar as performances da Adidas através da interpretação simbólica das gestualidades e figurino dos personagens que as usam no videoclipe. Problemática sustentada por Cardoso Filho (2014) quando afirma, baseado em estudiosos dos performance studies, que "toda e qualquer atividade humana pode ser estudada enquanto 
performance (...), na medida em que indicam uma determinada ação convencionalizada”. Os gestos e condutas desenvolvidos pelos rappers do Run DMC no videoclipe são entendidos como "objetivações e formas rítmicas que emprestam forma corporal a um discurso” (GEBAUER e WULF, 2004). Esses gestos materializam a construção de sentidos e valores culturais que podem ser evidenciados através das vozes, gestos, posicionamentos e enquadramentos de câmera, olhar dos artistas e personagens que participam dos videoclipes (GUTMANN, 2013). Assim, exercício interpretativo é empregado aqui no videoclipe My Adidas (1986), dirigido por Arthur King, a fim de responder algumas daquelas questões e traçar caminhos que contribuam para um melhor aprofundamento, dessa problemática, em pesquisas futuras.

\section{Trilhas metodológicas}

Como recorte metodológico, utilizamos o caminho traçado por Gutmann (2013, p. 3) para "refletir sobre os usos dos corpos falantes" feitos pela Adidas nos videoclipes do grupo "enquanto construtores de sentidos (ou nos termos de Martin-Barbero, como tecnicidades de ritualização de sentidos e valores...)" (GUTMANN, 2013, p. 3). Com isso, nosso objetivo, é compreender as estratégias comunicacionais da Adidas na construção e apropriação de valores culturais através das gestualidades expressas nas performances dos artistas ao utilizar a marca.

O videoclipe do Run DMC com a presença da marca é visto, aqui, como um produto que medeia as articulações "entre cultura, comunicação e política que põe em diálogo lógicas de produção e de consumo, formas industriais e matrizes culturais" conforme o mapa das mediações proposto por Martin-Barbero (GUTMANN, 2013, p. 4). O uso do mapa contribui, assim, para explorar os modos pelos quais lógicas de produção da Adidas e os formatos industriais do campo musical se articulam no gênero rap e se manifestam nas performances e gestualidades dos artistas nos videoclipes.

Pensar no videoclipe enquanto gênero midiático a partir do prisma do mapa das mediações permite estabelecer algumas relações que 
contribuem para uma análise mais objetiva e proveitosa para o propósito desse trabalho. $\mathrm{O}$ videoclipe não pode ser estudado como um formato isolado e independente de certas configurações impostas pela mídia, em sua relação com a cultura, indústria fonográfica e regras econômicas (JANOTTI JR., 2003, p. 36). Pois, conforme Soares (2007, p. 2) sinaliza, o videoclipe, assim como a canção que o origina, "está inserido dentro de uma lógica de produção da indústria fonográfica e, estando arraigada neste sistema produtivo, (...) o videoclipe é um lugar sintomático para identificar e problematizar as estratégias discursivas deste produto".

Isso não significa que desconhecemos os trabalhos que se aprofundam nos aspectos concernentes ao campo da linguagem audiovisual para estudo dos videoclipes (BARRETO, 2013; MACHADO, 2000) - nem que discordamos dos mesmos. O foco desse ensaio analítico é entender a construção de valores a partir da performance da marca Adidas no videoclipe do Run DMC, por isso os elementos da linguagem audiovisual são considerados tomando essa problemática cultural como predominante.

O mapa das mediações, então, torna-se uma perspectiva possível para investigação desse problema, uma vez que Martín-Barbero (2009) defende que há uma forte relação entre consumo, cultura e cotidiano que se interpenetram nos estudos da comunicação. Para ele, as relações entre Lógicas de Produção, Formatos Industriais, Competências de Recepção e Matrizes Culturais se dão pelas mediações da tecnicidade, ritualidade, socialidade e institucionalidade, respectivamente. Em seu famoso esquema, percebe-se a existência de dois eixos pelos quais essas mediações são estabelecidas. Um eixo sincrônico, entre as Lógicas de Produção e Competências de Recepção e outro diacrônico, entre Matrizes Culturais e Formatos Industriais.

O videoclipe é entendido aqui enquanto um formato industrial, instituído como um padrão a partir dos anos 1980, e que goza de uma longevidade até os tempos atuais ${ }^{4}$. Um formato que articula relações

\footnotetext{
${ }^{4}$ Embora padrões narrativos em videoclipes sejam identificados, há uma relação de estabilização/ desestabilização desse formato ao longo das explorações feitas dentro da cultura pop e das vanguardas expressivas.
} 


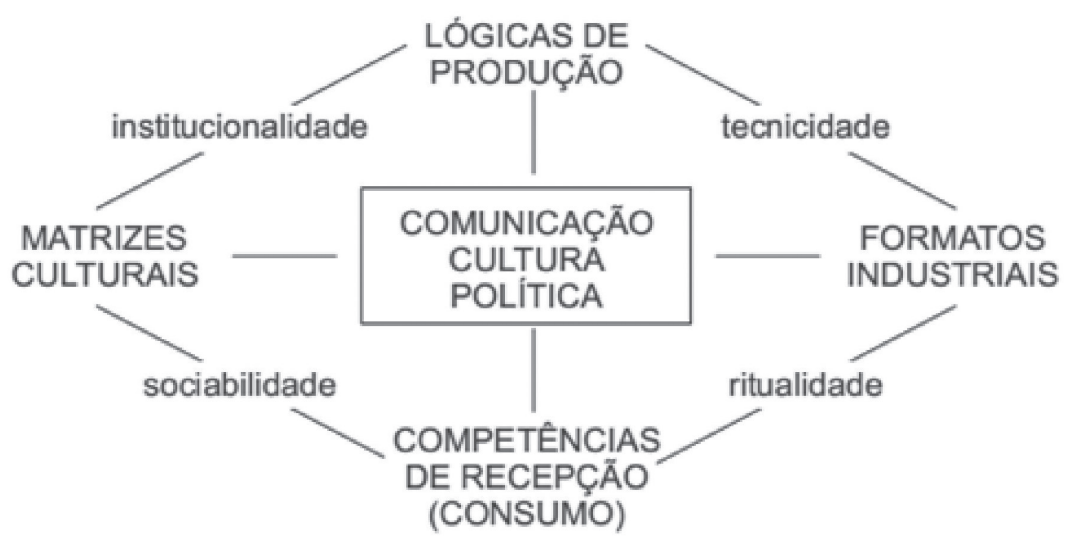

Figura 1. Reprodução do mapa das mediações.

Fonte: MARTÍN-BARBERO, 2009, p. 16.

simbólicas que permeiam o imaginário coletivo e, ao se relacionar com as competências de recepção dos espectadores, expressa determinados rituais de consumo. Uma ritualidade, portanto, que manifesta os padrões de recepção por meio dos quais os sujeitos irão estabelecer seus modos de leitura, visualização e interação com esse produto televisivo. Evidentemente, o formato videoclipe também está relacionado às Lógicas de Produção, de modo a expressar tecnicidades - as chamadas gramáticas de ação - que ordenam o formato industrial com determinados conteúdos (políticos, econômicos etc.).

O videoclipe é, então, esse lugar de interação entre as esferas de produção e de recepção e por meio dele se manifestam as lógicas produtivas dos interesses e desejos dos regimes de institucionalidades e suas estratégias de comunicabilidade. Nesse processo de tensionamento, afloram as socialidades e ritualidades constituintes dos processos de identificação. Pois, ainda segundo o autor, as lógicas de produção correspondem à estrutura empresarial em seus aspectos econômicos, ideológicos, suas "rotinas produtivas" e "competências comunicativas", que dizem respeito à sua "capacidade de interpelar/construir públicos, audiências, consumidores; e muito especialmente sobre sua competitividade tecnológica: 
uso da Tecnicidade dos quais depende hoje em grande medida a capacidade de inovar nos FI" (MARTÍN-BARBERO, 2009, p. 18).

Desta maneira, a análise da dimensão da tecnicidade no videoclipe pode ser feita a partir dos modos narrativos com que o mesmo configura as suas mensagens. Os recursos de edição, planos curtos e narrativa fragmentada podem indicar aquilo que se procura evidenciar em determinados aspectos da mensagem em detrimento de outros visuais e simbólicos, de menor importância. Perceber as tecnicidades imbricadas no videoclipe do Run DMC é uma das chaves para compreensão de como se engendram os mecanismos de percepção, de reconhecimento e de identidade da marca Adidas pelo texto midiático. Nessa perspectiva, ao tratar da tecnicidade, Ronsini (2010, p. 7) diz que:

Por sua centralidade na organização social, ela percorre o circuito inteiro, modelando a ritualidade, a socialidade e a institucionalidade, vale dizer, modela todas as relações porque se define como o estatuto social da técnica. Portanto, a tecnicidade pode ser compreendida em sentido estrito, como o aspecto textual, narrativo ou discursivo da mídia que funciona como organizador perceptivo.

A tecnicidade, nesse caminho de instituir as regras do jogo narrativo em que será possível a configuração das ritualizações de leitura e consumo midiáticos, coloca em evidência as formas de interação social e constituição de identificações. Já as ritualidades passam a atuar enquanto um recurso que ampara e sustenta os nexos simbólicos que medeiam as interações e os processos de recepção dos membros de uma determinada coletividade.

\section{A performance da Adidas como estratégia de ritualização de sentidos}

Uma das principais características da performance, é a "reiterabilidade". Através dela, um determinado comportamento pode se repetir indefinidamente sem ser considerado redundante - que autores oriundos do campo da linguística indicariam como uma herança da condição de 
possibilidade dos enunciados performativos: a repetição. Essa dimensão reiterável da performance foi aprofundada por Schechner (2006, p. 30, tradução nossa) através da ideia de comportamento restaurado:

Performances são feitas de porções de comportamento restaurado, mas cada performance é diferente de qualquer outra. Primeiro, determinadas porções do comportamento podem ser recombinadas em um número infinito de variações. Segundo, nenhum evento consegue copiar exatamente um outro evento. Não apenas o próprio comportamento - nuances de humor, tom de voz, linguagem corporal, e daí por diante, mas também a ocasião específica e o contexto fazem com que cada ocorrência seja única.

Erving Goffman (2012) é claramente a inspiração de muitos dos trabalhos sobre performances sociais. Sua proposição contribuiu para a compreensão da performance enquanto um instrumento de análise das relações socioculturais, já que, para ele, a performance corresponde a uma série de atividades desenvolvidas em uma determinada condição espaço-temporal diante da presença contínua de um conjunto de observadores e que exerce influência sobre os mesmos. Tratam-se dos esquemas de interpretação (quadros primários, segundo Goffman) que os indivíduos empregam para orientação nas situações sociais.

Essa definição é fundamental para a aproximação do conceito com as condições de ritualização que permitem a assimilação, a emergência de efeitos sensoriais e cognitivos - sobretudo no caso específico sobre o qual nos debruçaremos, o videoclipe do Run DMC e sua relação com a Adidas. Afinal, trata-se de um cenário propício para a encenação de certos comportamentos que se estabelecem entre persona e gênero musical, gênero musical e marca de acessórios para vestuário e mesmo entre o vestuário e a persona.

Como se trata de uma mediação entre as competências de recepção e os formatos industriais, a ritualidade implica pensar nas operações por meio das quais uma determinada expressão é apreendida. A condição comunicativa da performance implica, portanto, pensar a existência corporal de um sujeito para expressá-la que permite perceber como a Adidas 
convoca a presença do corpo e da voz dos rappers do Run DMC. Essa relação não se estabelece meramente para provocar na audiência aspectos ligados à sensibilidade corporal mas também para melhor fruição do texto, suas condições de consumo e reiterabilidade de comportamento dos espectadores.

O consumo é, na sociedade atual, um elemento central no processo de construção de identificações e de performances sociais. Nesse sentido, a posição que a Adidas passa a ocupar no universo simbólico do hip-hop passa pela própria performance do Run DMC e, portanto, uma das condições de existência da relação da marca com os membros das comunidades de fãs, militantes e ativistas da cultura hip-hop. Do mesmo modo em que pode perceber "o teatro como um espaço central da reprodução cultural e da exposição do corpo humano" (Hastrup apud CARLSON, 2011, p. 183, grifo nosso), existe uma exposição dos corpos e das gestualidades dos membros do Run DMC ao lado da Adidas, o que favorece uma determinada forma de percepção e reprodução cultural.

"A identidade é uma construção que se narra”, diz Canclini (2010, p. 129). Com isso, o autor corrobora com a discussão colocada neste artigo, uma vez que ele explica a influência midiática no processo de construção das identificações. Para ele, a mídia sempre exerceu um papel fundamental na construção da identidade e do sentido de cidadania. Ela convoca os sentimentos de partilhas de "hábitos e os gostos comuns, os modos de falar e de se vestir" que identificam e diferenciam um povo do outro. Com isso, penso que, através da disseminação proporcionada pelos videoclipes, o Run DMC, com suas formas de se vestir, de cantar e performatizar (LEAL, 2007), estabelece um novo sentido de reconhecimento, de identidade e de diferenciação entre os fãs dos guetos nova-iorquinos e os jovens dos demais grupos sociais - e até mesmo os de outras culturas e nações.

\section{My Adidas: um ensaio analítico}

Conforme argumentamos desde o início deste texto, a narrativa nos videoclipes do Run DMC se constitui numa fonte de disseminação de 
códigos culturais formadores das identidades dos fãs e adeptos da cultura hip-hop - trata-se de uma narrativa ritualizada, portanto. No momento em que o Run DMC expõe e ostenta sua admiração pela Adidas em seus videoclipes, ele realiza uma transição entre a realidade vivida deles (forma de vida) e a realidade da imagem (forma da imagem) e aquilo passa a fazer parte do imaginário coletivo de seus fãs (BRASIL, 2014). A performance do Run DMC é, assim, essa passagem entre o mundo ficcional e o mundo real, e quando os seus membros representam estão, simultaneamente, performatizando e recriando as suas próprias realidades. André Brasil aprofunda essa relação performática defendendo que:

a imagem faz conviver com sua dimensão representacional, uma dimensão performativa: ali, se performam formas de vida. Seja na mídia, nas artes visuais ou no cinema, não são poucas as experiências em que as imagens parecem não apenas representar ou figurar - não apenas, ressaltemos logo - mas inventar, produzir formas de vida, estas que mantêm com a obra uma relação de continuidade (em certos aspectos) e descontinuidade (em outros). Isso nos permitiria afirmar que as performances que ali se produzem (dos autores e dos personagens) estão, simultaneamente, no mundo vivido e no mundo imaginado, elas são, a um só tempo, forma de vida e forma da imagem (BRASIL, 2014, p. 133).

Desta forma, o videoclipe My Adidas gravado em 1986 pelo Run DMC através da Arista Records, traz uma sequência de cenas que configuram uma performance da marca. A Adidas, de maneira explícita e bastante expressiva, se vincula à narrativa da obra para se constituir como um elemento simbólico genuíno da cultura hip-hop por meio da associação direta com um dos grupos de rap mais influentes de sua época. É possível observar nas diversas cenas do videoclipe o enquadramento, em planos detalhe e médio, do tênis Adidas numa tentativa de demonstrar a imponência e importância da marca na performance do grupo.

Segundo Arlindo Machado (2000, p. 180), através de sua intensa exploração de efeitos videográficos que compõe uma linguagem marcada e caracterizada pela experimentação, planos curtos, descontinuidade, recortes, fragmentação e dispersão, o videoclipe estabelece a manutenção "(da reconhecibilidade) de, pelo menos, uma imagem, aquela 
do cantor ou da banda" por uma intenção comercial para a promoção dos discos e dos artistas, assim como a de "expandir seus meios de expressão" (BARRETO, 2005, p. 18). Com isto, esta "reconhecibilidade" apresentada por Machado não é, em My Adidas, apenas a do grupo, mas principalmente a da marca.

Conforme Barbara Smit apresenta em seu livro, a história deste videoclipe começa antes mesmo do Run DMC ser formado. A Adidas, no fim da década de 1970, enviou aos Estados Unidos um italiano chamado Angelo Anastasio. Sua função era a de promover a marca entre as celebridades americanas. No início dos anos 1980, ele se deparou com três rapazes negros que dançavam break no meio da rua e usavam tênis e calça da marca. A partir daí, o italiano passou a fornecer materiais da Adidas para os jovens até que os mesmos formaram o grupo Run DMC (SMIT, 2007).

No entanto, essa narrativa é posta em dúvida quando a jornalista Klein (2002) afirma que, inicialmente, a Adidas se recusou a patrocinar o Run DMC para não se vincular a uma estética negra e marginal. Segundo ela, os executivos da marca mudaram de ideia após serem convencidos pelos produtores dos rappers a assistir um show dos mesmos em que milhares de jovens exibiam seus tênis em resposta ao clamor da performance do grupo no palco.

Diante de versões diferentes para uma mesma história, o que se pode concluir é que, a partir de algum momento, a marca e o grupo estabeleceram uma relação de trocas simbólicas muito peculiares. Se por um lado a Adidas se vinculou ao universo simbólico da cultura hip-hop, por outro, o Run DMC adquiriu um símbolo expressivo de sua própria identidade. As cenas destacadas a seguir demonstram a intensidade dessa relação.

É interessante considerar que, apesar das sequências de imagens que destacam partes da letra da música, a narrativa do videoclipe não tem uma correspondência direta com o conteúdo do texto verbal musical. O videoclipe evoca características estéticas e narrativas de acordo com as configurações de gêneros típicas deste formato industrial. No entanto, a 
depender do contexto de fruição da obra e do grau de conhecimento de um determinado espectador, desinformado de que se trata de um videoclipe, ele pode facilmente ser percebido enquanto um filme publicitário da marca. O videoclipe My Adidas, com isto, é uma obra interessante para a discussão das noções de gêneros que evocam e delimitam os horizontes de expectativas e as ritualidades de recepção, ao tencionar as tecnicidades impostas pelas lógicas produtivas da indústria fonográfica.
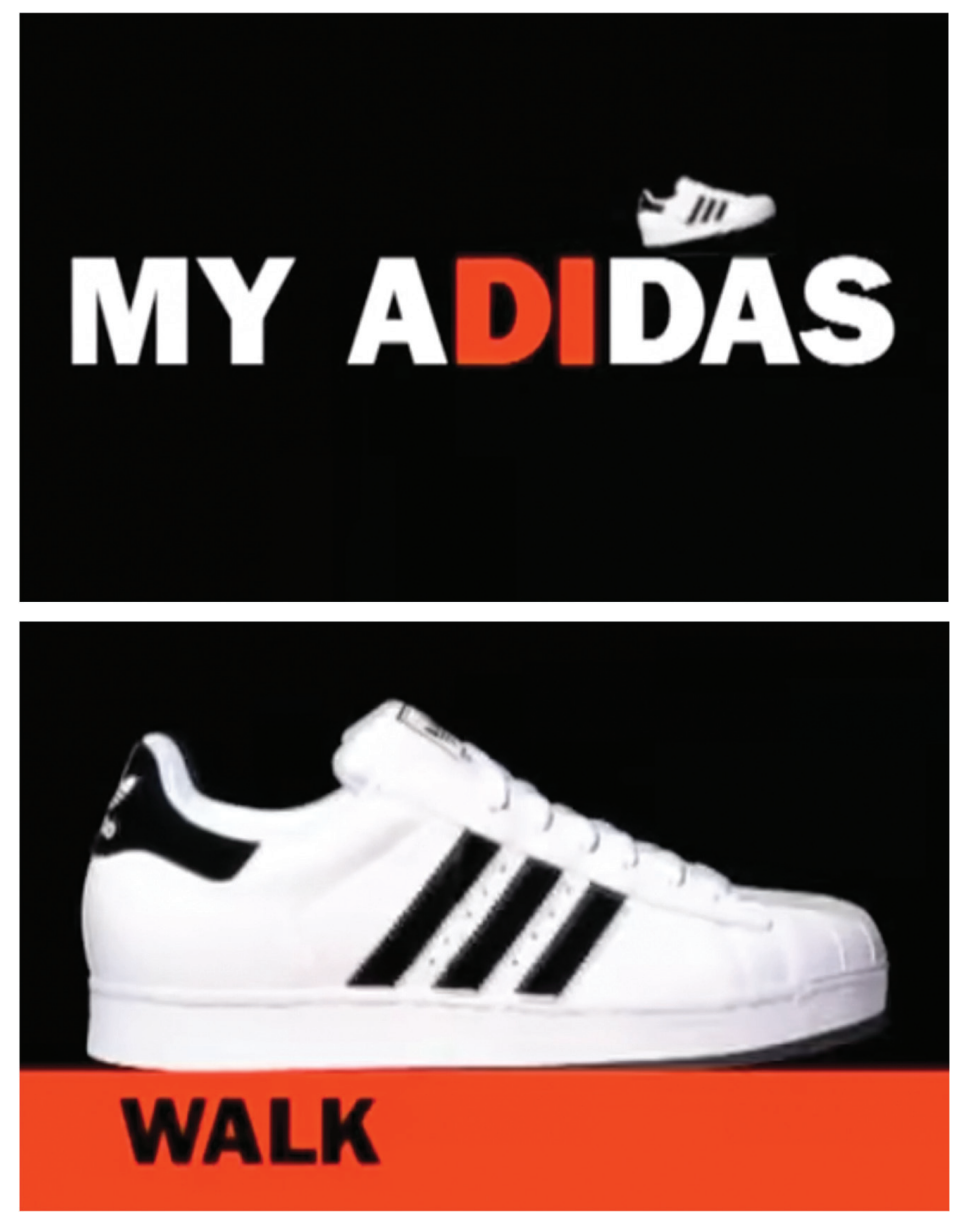

Figuras 2 e 3. Cenas do videoclipe My Adidas.

Fonte: YouTube. Disponível em: https://www.youtube.com/watch?v=vlhNs4Wzfkk. Acesso em: 08 abr. 2016. 
As primeiras cenas do videoclipe (Figuras 2 e 3 ) chamam atenção pela prioridade com que é dada à marca em detrimento, mesmo, da presença dos corpos dos artistas. O videoclipe é iniciado por uma animação tipográfica que forma o seu próprio título com um tênis da Adidas sobre ele. Em seguida, o tênis ganha certa projeção e ocupa cerca de $80 \%$ da tela. Só a partir deste momento é que surge Darryl "DMC" McDaniels com jaqueta, calça e tênis da marca. Os dois outros integrantes do grupo aparecem na sequência, conforme a Figura 4. Esta sequência de imagens, denota como a performance da marca parece convocar a presença dos corpos dos integrantes do Run DMC apenas como suporte de ostentação de suas próprias representações simbólicas.

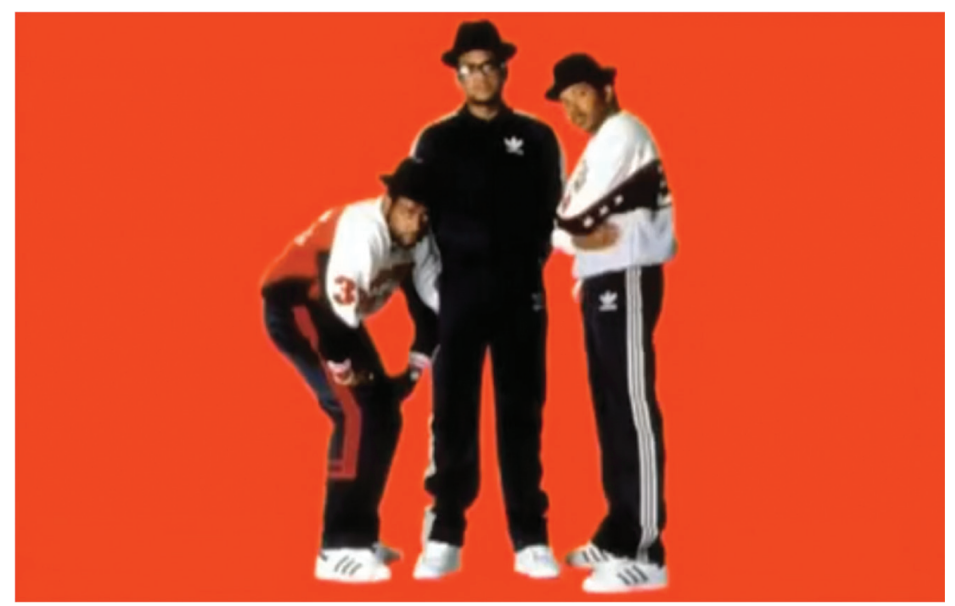

Figura 4. Darryl "DMC" McDaniels no centro, Jason "Jam Master Jay" Mizell a sua direita e Joseph "DJ Run" Simmons à esquerda Fonte: YouTube. Disponível em: https://www.youtube.com/watch?v=vlhNs4Wzfkk. Acesso em: 08 abr. 2016.

Na Figura 5, uma ilustração de um braço vestindo uma jaqueta da marca e empunhando um microfone é exibida. Neste momento, a voz de um dos rappers enuncia um verso que afirma seu comando, talvez, sobre a plateia ou sobre sua vida. Na Figura 6, a voz afirma que o rapper e a Adidas formam um bom time e que os dois caminham e rimam 
sempre juntos5. Essas imagens demonstram a competência requerida pela performance do "saber-fazer" e do "saber-dizer", na medida em que mais que simplesmente usar o Adidas, há uma espécie de articulação entre o tênis e o rapper e vice-versa.
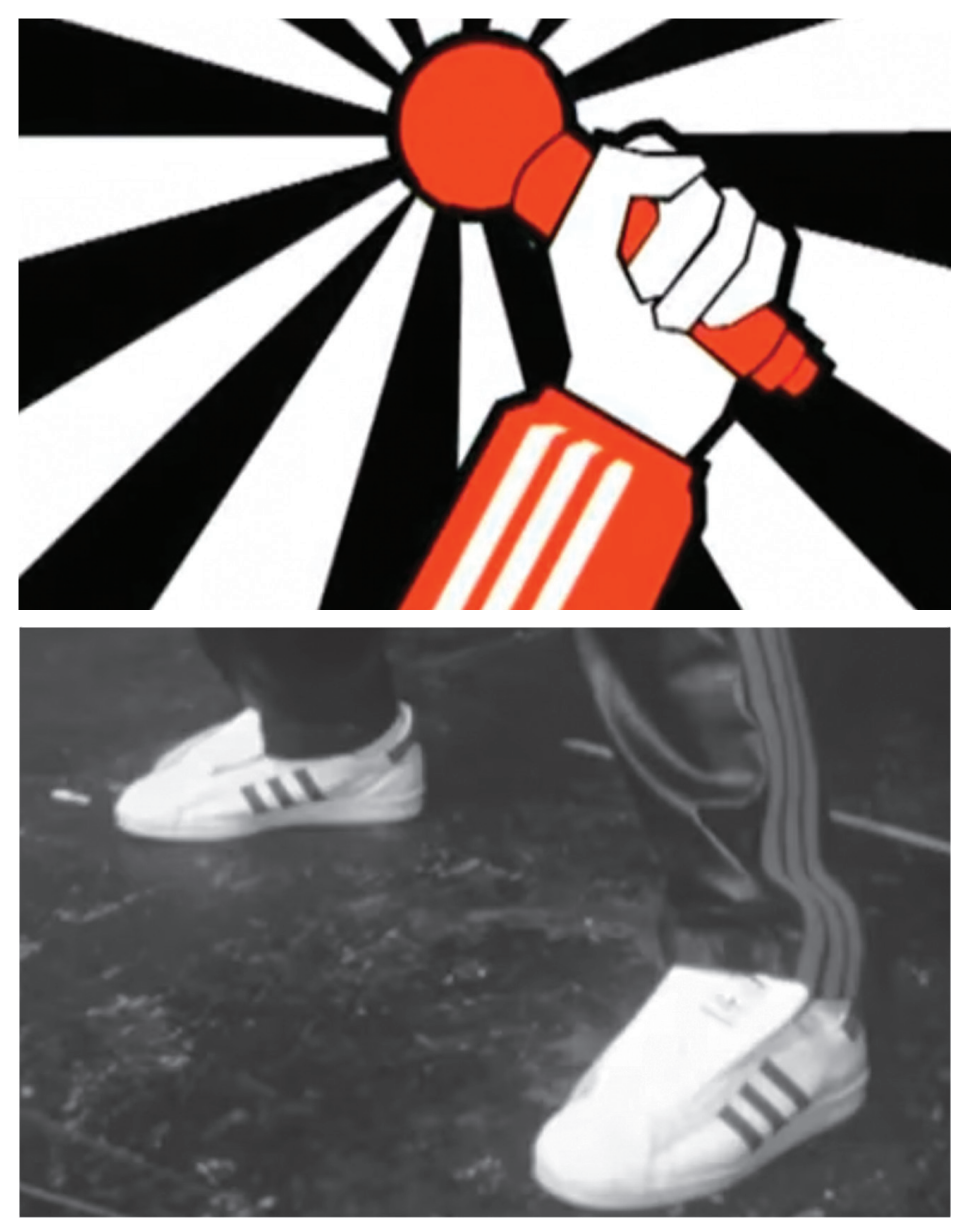

Figuras 5 e 6. Cenas do videoclipe My Adidas

Fonte: YouTube. Disponível em: https://www.youtube.com/watch?v=vlhNs4Wzfkk. Acesso em: 08 abr. 2016.

5 Trecho original da música My Adidas: "With mic in hand I cold took command / My Adidas and me both askin P / We make a good team My Adidas and me / We get around together, rhyme forever / And we won't be mad when worn in bad weather". 
Além disso, essas ações evocam a realização performática do "mostrar fazendo" e do "explicar mostrar fazendo" na perspectiva de Schechner (2006). Para este autor, o mostrar fazendo significa o "desempenhar: apontar, sobrelinhar, e exibir fazendo”. Por essa conceituação, o Run DMC exibe o seu fazer e a sua competência de saber-fazer, tanto o ato de cantar quanto o de sobreviver nas ruas, usando a marca como um amuleto, que protege e inspira suas performances. A performance da Adidas, ao convocar o corpo e a voz dos integrantes do Run DMC, parece se tornar uma espécie de musa inspiradora que passa a ser responsável por sua própria razão de existir.

Deste modo, as gestualidades expressas pelo Run DMC através da sua própria performance, no videoclipe, configuram a materialização de sua conduta e, ainda mais interessante, contribui significativamente para as performances desenvolvidas pela marca Adidas na sua relação com o gênero musical rap. Os gestos, entonação de voz e a postura evocam uma determinada forma de ritualização entre os fãs e os seus ídolos. Eles indicam o caminho a ser percorrido para aproximar um do outro e fazer de ambos, membros de uma mesma comunidade de sentidos e valores. Assim, Jean Galard ajuda a entender de que modo a performance convoca valores de gostos e sentidos cultivados pela gestualidade:

Se é verdade que toda reação é socialmente modelada, que nossos gestos, inclusive os mais elementares, são educados, a arte que se dedicasse a eles não contradiria o "natural", substituiria uma arte anterior, uma estética implícita, pouco consciente, que regula o porte e a atitude, a continência e as conveniências, que subtende a exigência da contenção, quando não do comedimento (GALARD, 2008, p. 21).

As Figuras 7 e 8 evidenciam bem o poder dos gestos performatizados pelo Run DMC em relação aos seus fãs. Nelas, a plateia desempenha uma ação vibrante que denota a paixão que possui pela marca e os valores que ela evoca quando convocada pelos rappers a exibirem os seus tênis. 

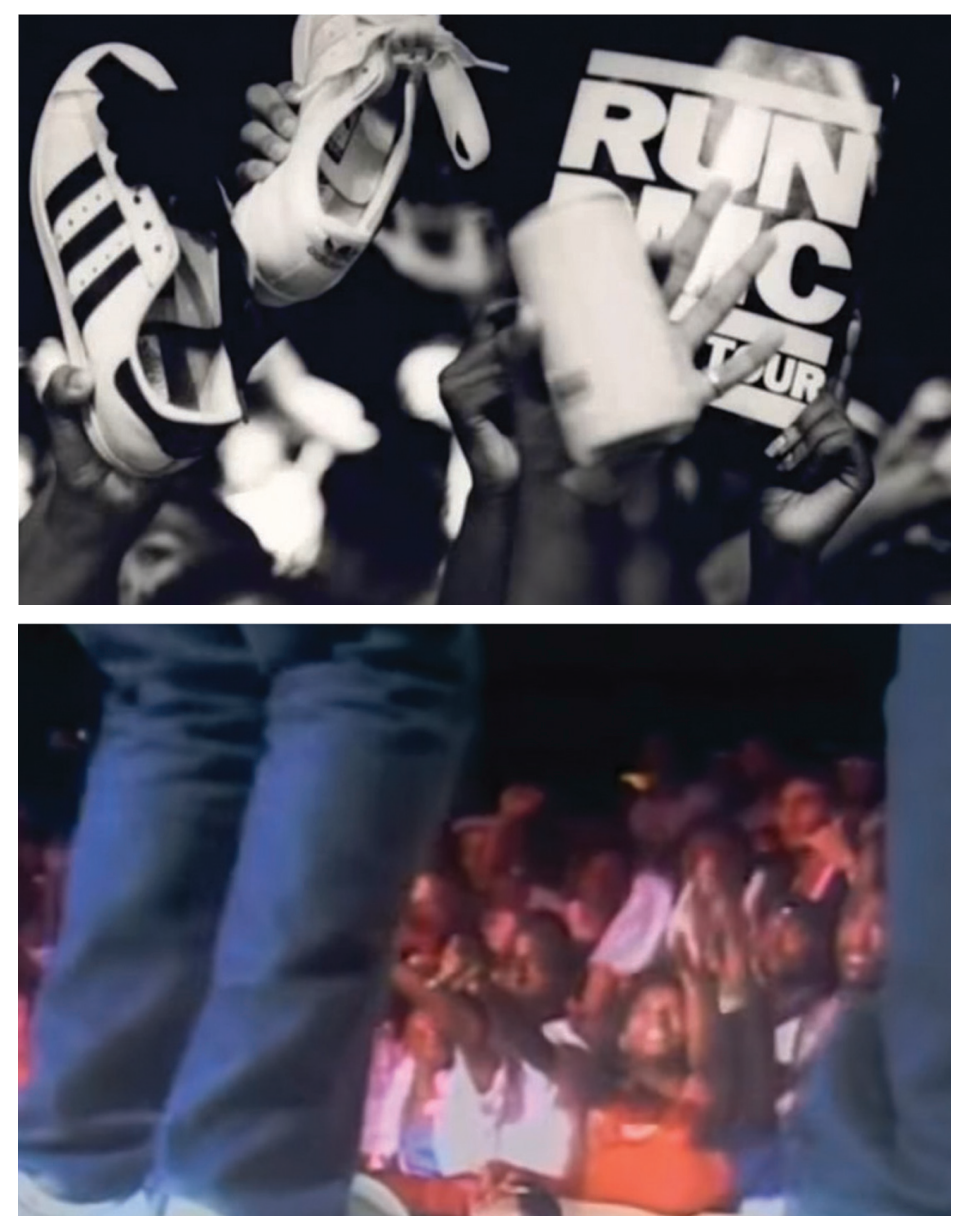

Figuras 7 e 8. Cenas do videoclipe My Adidas

Fonte: YouTube. Disponível em: https://www.youtube.com/watch?v=vIhNs4Wzfkk. Acesso em: 08 abr. 2016.

Já as Figuras 9 e 10 sugerem a configuração de um cenário urbano enquanto um espaço social a ser performatizado o uso da Adidas, por meio de uma ação naturalizada e cotidiana que suscita no espectador a identificação não somente com o ambiente social ao qual está inserido, mas também com a sua própria relação de performatizar aquele papel social que se estabelece como horizonte de expectativa a ser seguido pelo sujeito através do consumo da marca (SOARES, 2005, p. 3). 

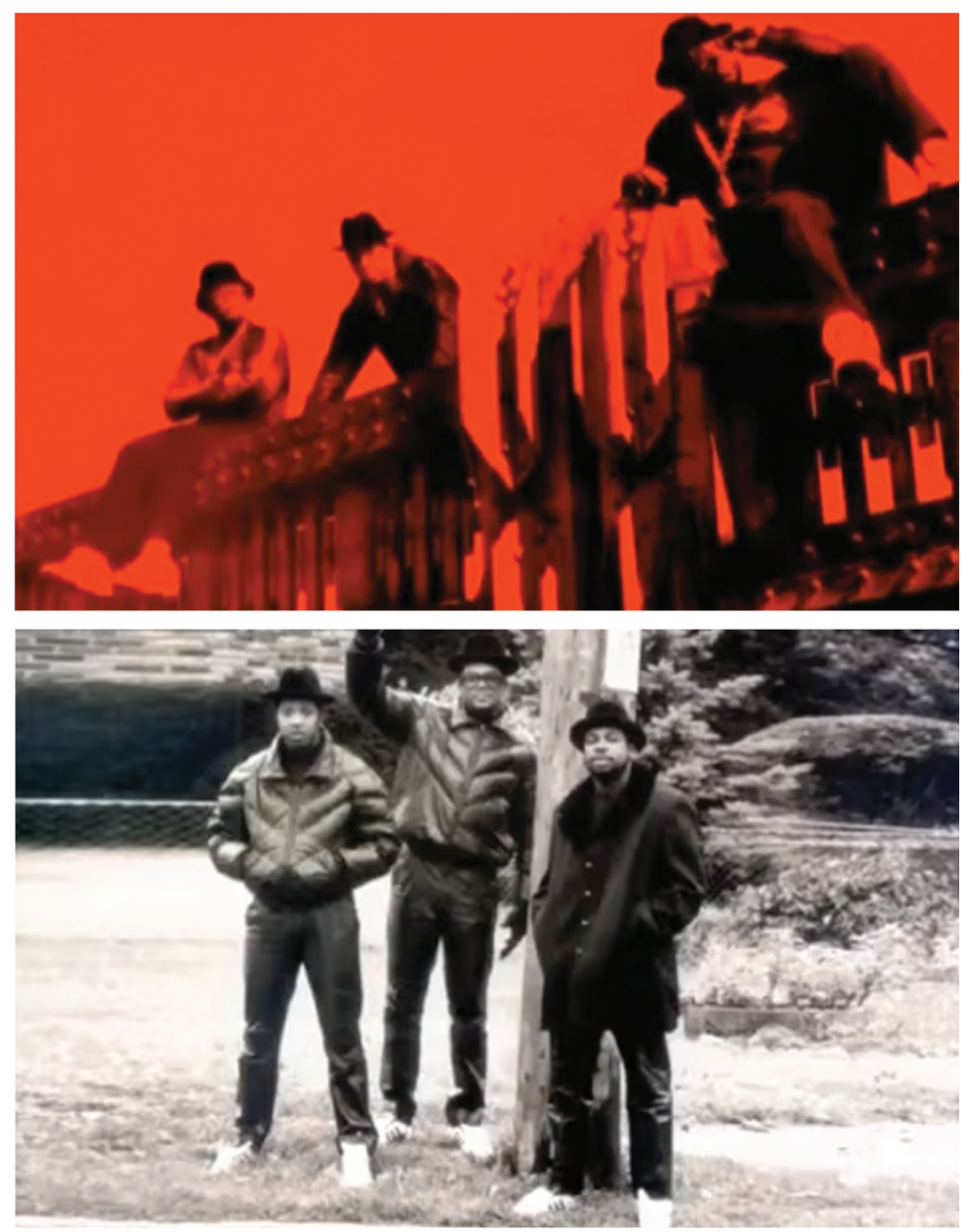

Figuras 9 e 10. Cenas do videoclipe My Adidas

Fonte: YouTube. Disponível em: https://www.youtube.com/watch?v=vIhNs4Wzfkk. Acesso em: 08 abr. 2016.

Assim, ao se analisar algumas das cenas do videoclipe My Adidas é possível perceber que um forte processo de identificação como grupo é forjado pelo consumo, e, com ela, a marca vincula-se de maneira expressiva às práticas sociais performatizadas pelos jovens adeptos da cultura hip-hop que o Run DMC representa. A performance restaurada dos seus integrantes ao usar e ostentar a marca estabelece uma ritualização de 
sentidos e de partilha de gostos que são intensificados e potencializados pela narrativa do videoclipe. A marca, assim, busca garantir a sua popularização incorporando-se aos códigos simbólicos que identificam e diferenciam os fãs e membros dos grupos de referência da cultura hip-hop. As Figuras 11 e 12 contribuem para a percepção da influência exercida pela Adidas ao performatizar uma estética urbana que se manifesta na representação dos corpos e das vozes dos rappers.
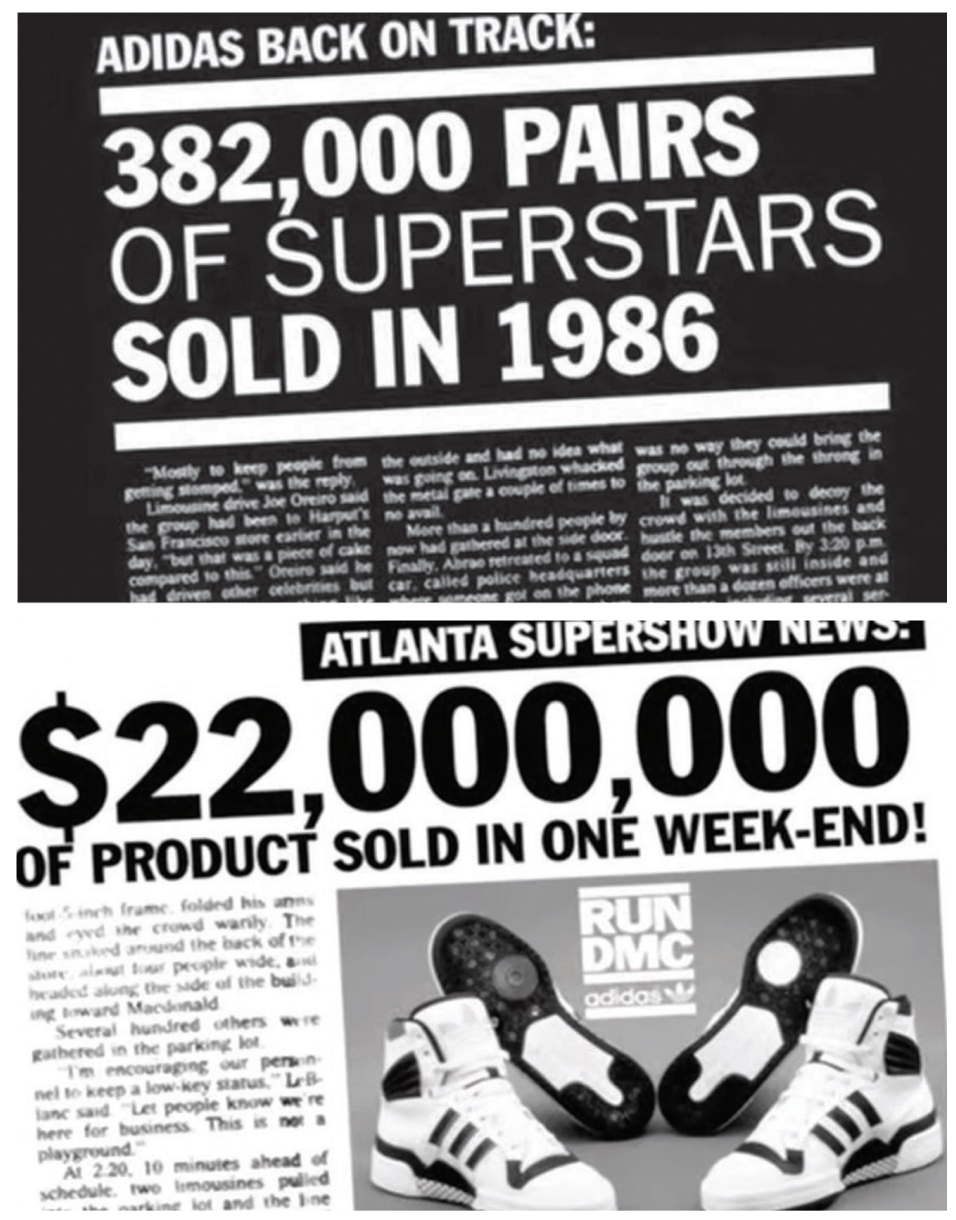

Figuras 11 e 12. Cenas do videoclipe My Adidas

Fonte: YouTube. Disponível em: https://www.youtube.com/watch?v=vIhNs4Wzfkk. Acesso em: 08 abr. 2016. 
O esforço de análise desempenhado neste texto tentou demonstrar os modos pelos quais as estratégias comunicativas da Adidas, ao convocar a presença do Run DMC ostentando o consumo da marca, foram elaboradas. O uso do mapa das mediações, apesar de necessitar de maiores aprofundamentos em estudos futuros, contribuiu para a compreensão das relações impostas entre as tecnicidades e as ritualidades e como estas são manifestadas pela performance da marca em sua interação com o grupo e os seus fãs.

\section{Considerações finais}

Percebemos, ao fim deste ensaio analítico, que a narrativa construída pelo videoclipe My Adidas funciona, ao menos, de dois modos. $\mathrm{O}$ primeiro modo é aquele em que as ações em curso apresentadas pelos artistas apontam para gestos, comportamentos e até mesmo condutas que os ouvintes de rap e adeptos da cultura hip-hop desenvolvem em seus cotidianos. Nesse sentido, podemos ler o videoclipe como uma performance do gosto, como uma espécie de exercício dos padrões de consumo de uma comunidade de sentidos, que partilha formas de interpretação do mundo.

O segundo modo, e aquele que nos interessava especificamente neste ensaio, é aquele pelo qual a própria marca Adidas apresenta uma relação com esse gênero musical e, sobretudo, com o Run DMC, de maneira a construir uma trajetória para a própria marca. Entendemos, portanto, que a forma como ela se insere (ora reafirmando, ora tensionando) no diálogo com o rap demonstra uma performance da marca, que permite discutir o modo como esses agentes do campo da comunicação reconstroem constantemente suas lógicas de produção ${ }^{6}$.

O primeiro modo de funcionamento está mais próximo das chamadas formas de vida enquanto o segundo modo de funcionamento das formas da imagem (BRASIL, 2014). No primeiro modo de funcionamento são

\footnotetext{
${ }^{6} \mathrm{O}$ aprofundamento desta pesquisa foi feito na dissertação de mestrado de Marcio Barbosa (2016) através da compararação das performances presentes nos videoclipes My Adidas e Walk This Way com a própria campanha publicitária desenvolvida pela Adidas na época de lançamento dos clipes.
} 
os gestos de vida que se incorporam na performance dos artistas, incutindo ali as expressões físicas (e por que não, encenadas?) de um cotidiano. No segundo modo de funcionamento são os mecanismos de sedução das imagens que instruem os gestos e as expressões, estetizando o cotidiano daqueles grupos. Essa relação entre os modos de funcionamento é intercambiável e interdependente.

\section{Referências}

BARBOSA, M. Adidas e o Hip-Hop: mediação cultural e performances através de videoclipes e campanhas publicitárias. Salvador: UFBA, 2016. 128 f. Dissertação (mestrado em Comunicação) - Programa de Pós-Graduação em Comunicação e Cultura Contemporâneas, Faculdade de Comunicação, Universidade Federal da Bahia, Salvador, 2016.

BARRETO, R. R. A Fabricação do ídolo pop: a análise textual de videoclipes e a construção da Imagem de Madonna. Salvador: UFBA, 2005. 198 f. Dissertação (mestrado em Comunicação) - Programa de Pós-Graduação em Comunicação e Cultura Contemporâneas, Faculdade de Comunicação, Universidade Federal da Bahia, Salvador, 2005.

BARRETO, R. R. Parceria Videoclípica: Annie Lennox \& Sophie Müller. CineCachoeira - Revista de Cinema da UFRB, v. III, p. 8, 2013.

BRASIL, A. A performance: entre o vivido e o imaginado. In: PICADO, B. et al. (Org.). Experiência Estética e Performance. Salvador: EdUFBA, 2014.

CANCLINI, N. G. Consumidores e cidadãos: conflitos multiculturais da globalização. Rio de Janeiro: UFRJ, 2010.

CARDOSO FILHO, J. Ao vivo em Pompéia ou do Lado escuro da Lua? Heranças da performance do Pink Floyd. In: PICADO, B. et al (Org.). Experiência Estética e Performance. Salvador: EdUFBA, 2014.

CARLSON, M. O Entrelaçamento dos Estudos Modernos da Performance e as Correntes Atuais em Antropologia. Revista Brasileira de Estudos da Presença, Porto Alegre, v. 1, n. 1, p. 164-188, jan./jun. 2011. Disponível em: http://www.seer.ufrgs.br/presenca/ article/view/21512. Acesso em: 2 set. 2014.

GALARD, J. A beleza dos gestos: uma estética das condutas. São Paulo: Edusp, 2008.

GEBAUER, G; WULF, C. Mímese na cultura: agir social, rituais e jogos, produções estéticas. São Paulo: Annablume: 2004.

GOFFMAN. E. Os quadros na experiência social: uma perspectiva de análise. Petrópolis: Vozes, 2012. 
GUTMANN, J. F. Entre tecnicidades e ritualidades: formas contemporâneas de performatização da notícia na televisão. In: XXII ENCONTRO ANUAL DA COMPÓS. Anais... Salvador: Compós, 2013. Disponível em: http://compos.org.br/data/biblioteca_2074.pdf. Acesso em: 18 jul. 2014.

KLEIN, N. Sem logo: a tirania das marcas em um planeta vendido. Rio de Janeiro: Record, 2002.

LEAL, S. J. M. Acorda hip-hop!: despertando um movimento em transformação. Rio de Janeiro: Aeroplano, 2007.

MACHADO, A. A televisão levada a sério. São Paulo: Senac, 2000.

MARTÍN-BARBERO, J. Dos meios às mediações: comunicação, cultura e hegemonia. Rio de Janeiro: UFRJ, 2009.

RONSINI, V. V. M. A perspectiva das mediações de Jesús Martín-Barbero (ou como sujar as mãos na cozinha da pesquisa empírica de recepção). In: XIX ENCONTRO ANUAL DA COMPÓS. Anais... Rio de Janeiro: Compós, 2010. Disponível em: http:// compos.com.puc-rio.br/media/gt12_veneza_ronsini.pdf. Acesso em: 15 ago. 2014.

SCHECHNER, R. Performance studies: an introduction. 2. ed. Nova York: Londres: Routledge, 2006.

SMIT, B. Invasão de campo: Adidas, Puma e os bastidores do esporte moderno. Rio de Janeiro: Zahar, 2007.

SOARES, T. O videoclipe no horizonte de expectativas do gênero musical. E-Compós, v. 4, p. 1-18, dez. 2005. Disponível em: http://www.compos.org.br/seer/index.php/e-compos/article/viewFile/52/52. Acesso em: 11 set. 2013.

SOARES, T. O videoclipe como articulador dos gêneros televisivo e musical. In: IX Congresso Brasileiro de Ciências da Comunicação da Região Nordeste. Anais... Salvador: Intercom, 2007. Disponível em: http://www.intercom.org.br/papers/regionais/ nordeste2007/resumos/R0264-1.pdf. Acesso em: 08 abr 2016.

SOARES, T. MANGABEIRA, A. Alice através...: Televisão, redes sociais e performance num produto televisivo expandido. Contemporanea - Revista de Comunicação e Cultura, v. 10, n. 02, p. 272-288, 2012. Disponível em: http://www.portalseer.ufba.br/index. php/contemporaneaposcom/issue/view/649. Acesso em: 20 mai de 2014.

STOUTE, S. The Tanning of America: How Hip-Hop Created a Culture That Rewrote the Rules of the New Economy. Nova York: Gotham Books, 2011. 


\section{Sobre os autores}

Marcio Ricardo Silva Barbosa - Mestre em Comunicação e Cultura Contemporâneas pela Universidade Federal da Bahia (UFBA). Supervisor de marketing e comunicação da Associação Bahiana de Medicina.

Jorge L. C. Cardoso Filho - Doutor em Comunicação Social pela Universidade Federal de Minas Gerais (UFMG). Docente no Centro de Artes, Humanidades e Letras da Universidade Federal do Recôncavo da Bahia (UFRB) e do Programa de Pós-graduação em Comunicação e Cultura Contemporâneas (UFBA).

Data de submissão: 25/05/2015

Data de aceite: $31 / 08 / 2015$ 